\title{
Concurrent System Engineering and Risk Reduction for Dual-Band (RF/optical) Spacecraft Communications
}

Karl B. Fielhauer and Bradley G. Boone

Johns Hopkins University, Applied Physics Laboratory, Laurel, Maryland

Daniel E. Raible

Glenn Research Center, Cleveland, Ohio 


\section{NASA STI Program . . . in Profile}

Since its founding, NASA has been dedicated to the advancement of aeronautics and space science. The NASA Scientific and Technical Information (STI) program plays a key part in helping NASA maintain this important role.

The NASA STI Program operates under the auspices of the Agency Chief Information Officer. It collects, organizes, provides for archiving, and disseminates NASA's STI. The NASA STI program provides access to the NASA Aeronautics and Space Database and its public interface, the NASA Technical Reports Server, thus providing one of the largest collections of aeronautical and space science STI in the world. Results are published in both non-NASA channels and by NASA in the NASA STI Report Series, which includes the following report types:

- TECHNICAL PUBLICATION. Reports of completed research or a major significant phase of research that present the results of NASA programs and include extensive data or theoretical analysis. Includes compilations of significant scientific and technical data and information deemed to be of continuing reference value. NASA counterpart of peer-reviewed formal professional papers but has less stringent limitations on manuscript length and extent of graphic presentations.

- TECHNICAL MEMORANDUM. Scientific and technical findings that are preliminary or of specialized interest, e.g., quick release reports, working papers, and bibliographies that contain minimal annotation. Does not contain extensive analysis.

- CONTRACTOR REPORT. Scientific and technical findings by NASA-sponsored contractors and grantees.
- CONFERENCE PUBLICATION. Collected papers from scientific and technical conferences, symposia, seminars, or other meetings sponsored or cosponsored by NASA.

- SPECIAL PUBLICATION. Scientific, technical, or historical information from NASA programs, projects, and missions, often concerned with subjects having substantial public interest.

- TECHNICAL TRANSLATION. Englishlanguage translations of foreign scientific and technical material pertinent to NASA's mission.

Specialized services also include creating custom thesauri, building customized databases, organizing and publishing research results.

For more information about the NASA STI program, see the following:

- Access the NASA STI program home page at http://www.sti.nasa.gov

- E-mail your question to help@sti.nasa.gov

- Fax your question to the NASA STI Information Desk at 443-757-5803

- Phone the NASA STI Information Desk at 443-757-5802

- Write to: STI Information Desk NASA Center for AeroSpace Information 7115 Standard Drive Hanover, MD 21076-1320 


\section{Concurrent System Engineering and Risk Reduction for Dual-Band (RF/optical) Spacecraft Communications}

Karl B. Fielhauer and Bradley G. Boone

Johns Hopkins University, Applied Physics Laboratory, Laurel, Maryland

Daniel E. Raible

Glenn Research Center, Cleveland, Ohio

Prepared for the

2012 Aerospace Conference

sponsored by IEEE and AES

Big Sky, Montana, March 3-10, 2012

National Aeronautics and

Space Administration

Glenn Research Center

Cleveland, Ohio 44135 
Level of Review: This material has been technically reviewed by technical management.

Available from

NASA Center for Aerospace Information 7115 Standard Drive

Hanover, MD 21076-1320
National Technical Information Service 5301 Shawnee Road Alexandria, VA 22312

Available electronically at http://www.sti.nasa.gov 


\title{
Concurrent System Engineering and Risk Reduction for Dual-Band (RF/Optical) Spacecraft Communications
}

\author{
Karl B. Fielhauer and Bradley G. Boone \\ Johns Hopkins University \\ Applied Physics Laboratory \\ Laurel, Maryland 20723 \\ Daniel E. Raible \\ National Aeronautics and Space Administration \\ Glenn Research Center \\ Cleveland, Ohio 44135
}

\begin{abstract}
This paper describes a system engineering approach to examining the potential for combining elements of a deepspace RF and optical communications payload, for the purpose of reducing the size, weight and power burden on the spacecraft and the mission. Figures of merit and analytical methodologies are discussed to conduct trade studies, and several potential technology integration strategies are presented. Finally, the NASA Integrated Radio and Optical Communications (iROC) project is described, which directly addresses the combined RF and optical approach.
\end{abstract}

\subsection{Introduction}

Space-based optical communications is an important technology for our nation in terms of international technological leadership. The U.S. Government is actively developing space-based optical communications payloads for both national security and high rate scientific data return missions to include near Earth and deep space applications. NASA has yet to fly a space-based optical communications payload, however several are currently in flight-development (Refs. 1 to 6), and the DoD has successfully flown GEO-Lite. Governments around the globe, including the U.S., are planning to implement space-based optical communications systems for many reasons, including: 1) access to unlimited and unregulated spectral bandwidth 2) physical layer immunity to detection and interference (intentional and otherwise) as well as intercept security 3) diverse and mobile ground stations sites for communications security and survivability, 4) high accuracy navigation capabilities such as ranging and 5) the potential for mass and power savings over RF technology.

While the U.S. Government has made significant investments in space-based optical communications, and has enjoyed in-flight success, technological leadership will be limited due to the number of flight opportunities that will accept the penalties of including both RF and optical communications payloads, performance benefits that are onpar with state of the art RF Ka-Band technology, and a required major investment in a new optical ground-based infrastructure. By addressing the current performance limitations and recognizing that $\mathrm{RF}$ and optical communications must coexist for the foreseeable future, a path to technological leadership is realizable.

\subsection{Current Optical Versus RF Space Based Communications System Design}

To better understand current space-based optical communications system architectures, a side-by-side comparison to RF must be undertaken. A Figure of Merit (FoM) must be established for a direct comparison to both technologies at the system level, independent of distance. The system-level metric must include the space-base terminal performance (be it RF or optical) and the ground receiver aperture and performance.

$$
\operatorname{FoM}(\mathrm{dB})=10 * \log \left(\frac{D^{2} * b p s_{\mathrm{Max}}}{\text { mass } * \text { power }}\right)
$$

Equation (1) represents a method for direct comparison of optical and RF communications systems anywhere in the solar system, where $D$ represents the distance between the terminal apertures, $\mathrm{bps}_{\mathrm{Max}}$ is the maximum transmitted information rate, mass $(\mathrm{kg})$ and power (Watts). Equation (1) does not directly account for availability of the link due to interference from cloud cover.

Figure 1 represents the FoM for flight missions both currently in production or recently proposed for lunar and Mars exploration (Refs. 7 to 9). As can be seen, optical communications systems for these missions were, at best, no better than a comparable Ka-Band system designs and, at half as efficient. The Ka-Band missions were not limited to the spectral bandwidth allocated by international agreement, but 


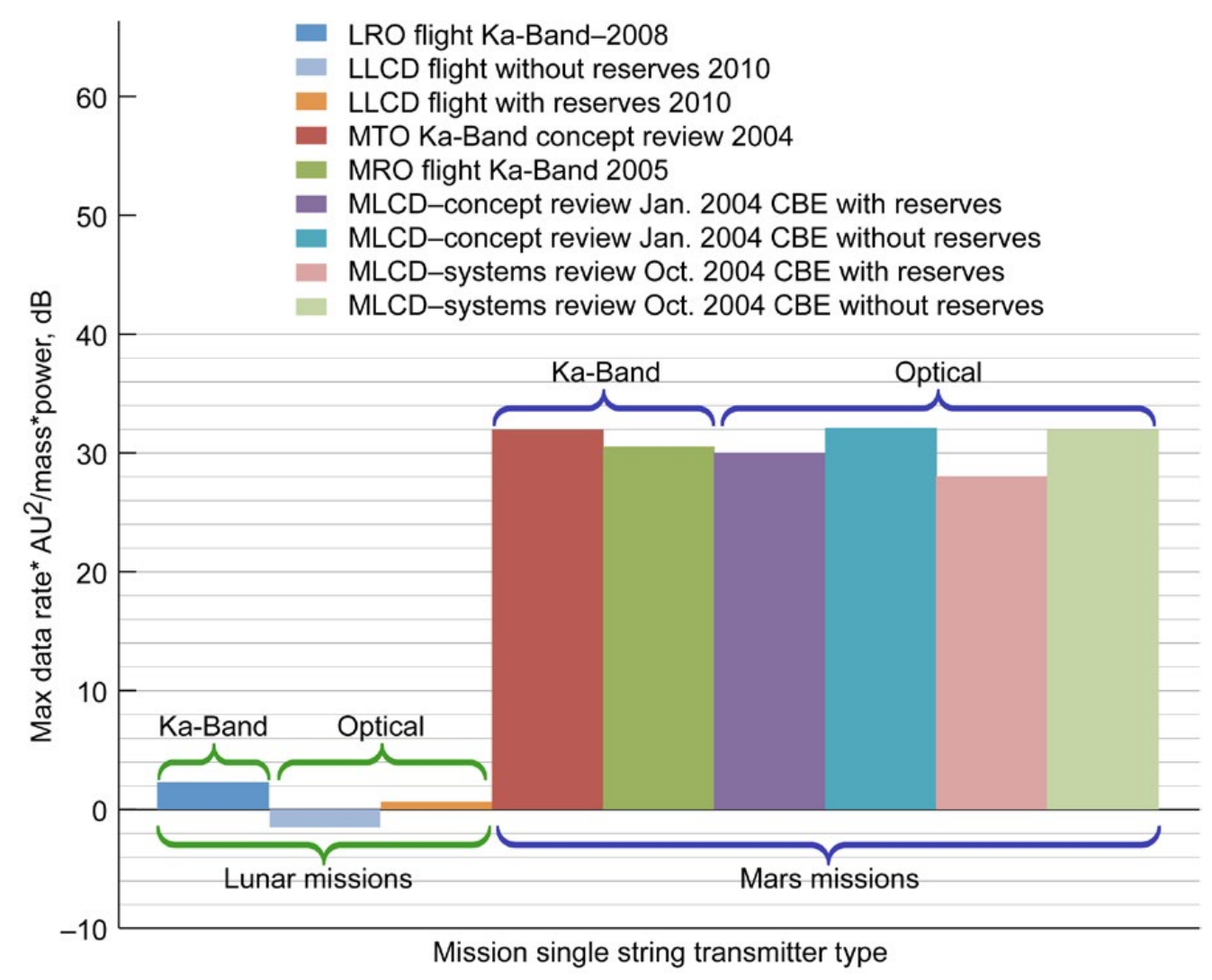

Figure 1.-FoM for Ka-Band and Optical Communication Systems for Lunar and Mars Missions.

were allowed to grow to the capability supported by the link budget. This was to support a direct technology comparison. The comparison also does not deduct for availability for the optical link, but does penalize the Ka-Band link for an availability of 90 percent. Both the optical and RF links have $3 \mathrm{~dB}$ available margin. The optical communications system, however, represents a stand-alone terminal design and must be supported by an additional Ka-band or X-band communications systems due to the need for all-weather communications.

Figure 2 represents the FoM applied to a current Ka-band system architecture as compared to optical designs under consideration for Mars missions in 2018. This system represents an 11 to $16 \mathrm{~dB}$ advantage over a Ka-Band system that is not constrained by spectrum and with no consideration of optical availability. Again, this candidate architecture also must support an additional Ka-Band or X-Band communications system for all-weather communications. Mission designers are very concerned about the increased burden of size, weight and power (SWaP) that an optical communications system will require despite the perceived benefit. In fact, SWaP has had a significant impact on space based optical communications technology transition to fully support scientific missions for NASA in both a support and primary role.

A rigorous systems engineering methodology, concurrent with technology innovations, such as an integrated dual-band RF and optical terminal (currently at TRL-2), will lead to scalable designs, will minimize SWaP and account for the constraints of current and future missions; namely that optical and RF communications systems will both be flown together for the foreseeable future. This approach offers a bridge between the RF based network integration underway at NASA, and the emerging optical capabilities. In order for space-based optical communications to become competitive and warrant the new ground based infrastructure investment will require performance and scalability well beyond the FoM of $43.6 \mathrm{~dB}$ currently planned, with FoMs exceeding $55 \mathrm{~dB}$ for Mars-class missions. Optical and RF must coexist, but with limited spacecraft burden.

\subsection{Systems Engineering Path Forward}

System development methods and practices have yet to be fully integrated into a rigorous methodology for communications system analysis, trades, design and risk 


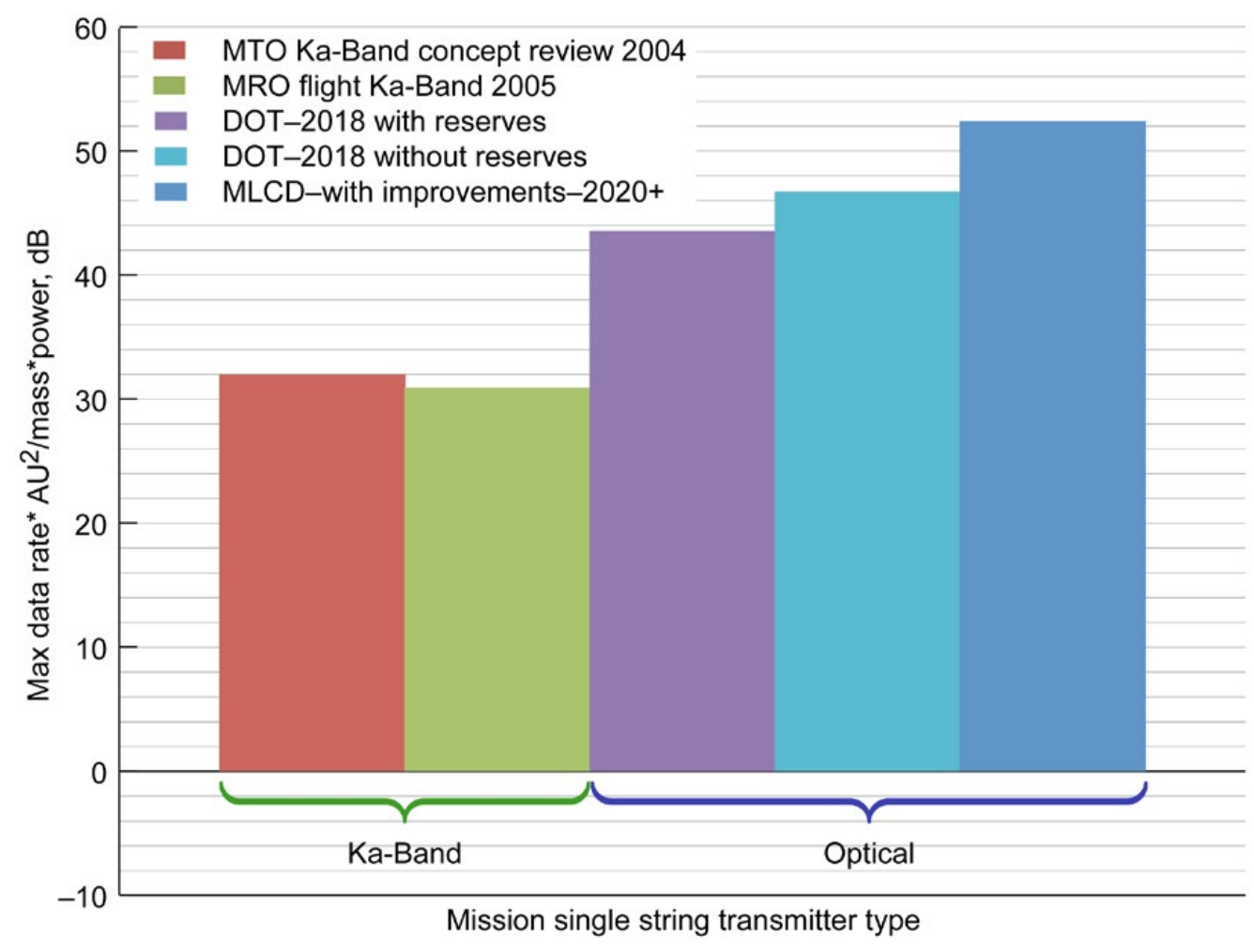

Figure 2.-FoM for Ka-band and Optical Performance for future Mars Communications Systems.

reduction. APL has defined a dual-band terminal trade methodology that encompasses link performance, (SWaP), materials and design, and path phenomenology and impairments. A mock up and schematic view of an integrated aperture example is shown in Figure 3 (Ref. 10).

Current interest from NASA poses a potential requirement to determine the mission utility of a dual-band (optical/RF) lightweight scalable communications payload in terms of challenging performance criteria for data rate $(1 \mathrm{Gbps})$ and pointing (300 to $1200 \mathrm{nrad}$ ), and reduced SWaP using new materials and designs, which will also require specific component TRL risk-reduction efforts.

These studies so far have uncovered some top-level results, which are:

- Individual component technologies (dual-band apertures, lightweight materials, reusable rad-hard by design (RHBD) digital core processors, 1 Gbps modulators) are within reach of timely risk reduction by 2014 to achieve significant (50 to 75 percent) mass reduction over current reference designs
- Integration risk is challenging because deep space pointing requirements can be tight (as low as $300 \mathrm{nrad}$ RMS at Mars) for larger apertures with lightweight materials, although there may exist some synergies between the RF and optical acquisition systems

- Specific component properties require empirical validation, including skin depth, RMS surface roughness, and dichroic component efficiencies for frequency selective surfaces (FSS)

- Increasing laser transmitter power and wall-plug efficiencies will enable a more scalable dual-band design

- A more rigorous methodology is needed to provide a more traceable cost-benefit trade for innovations in materials and design

- A more complex dual-band link loss management scheme should be simulated and implemented to optimally allocate data rates between bands

- The impact of lightweight materials on antenna/ telescope and structural alignment and line of sight (LoS) jitter, particularly from solar loading and vibration transmissibility, remain to be determined 

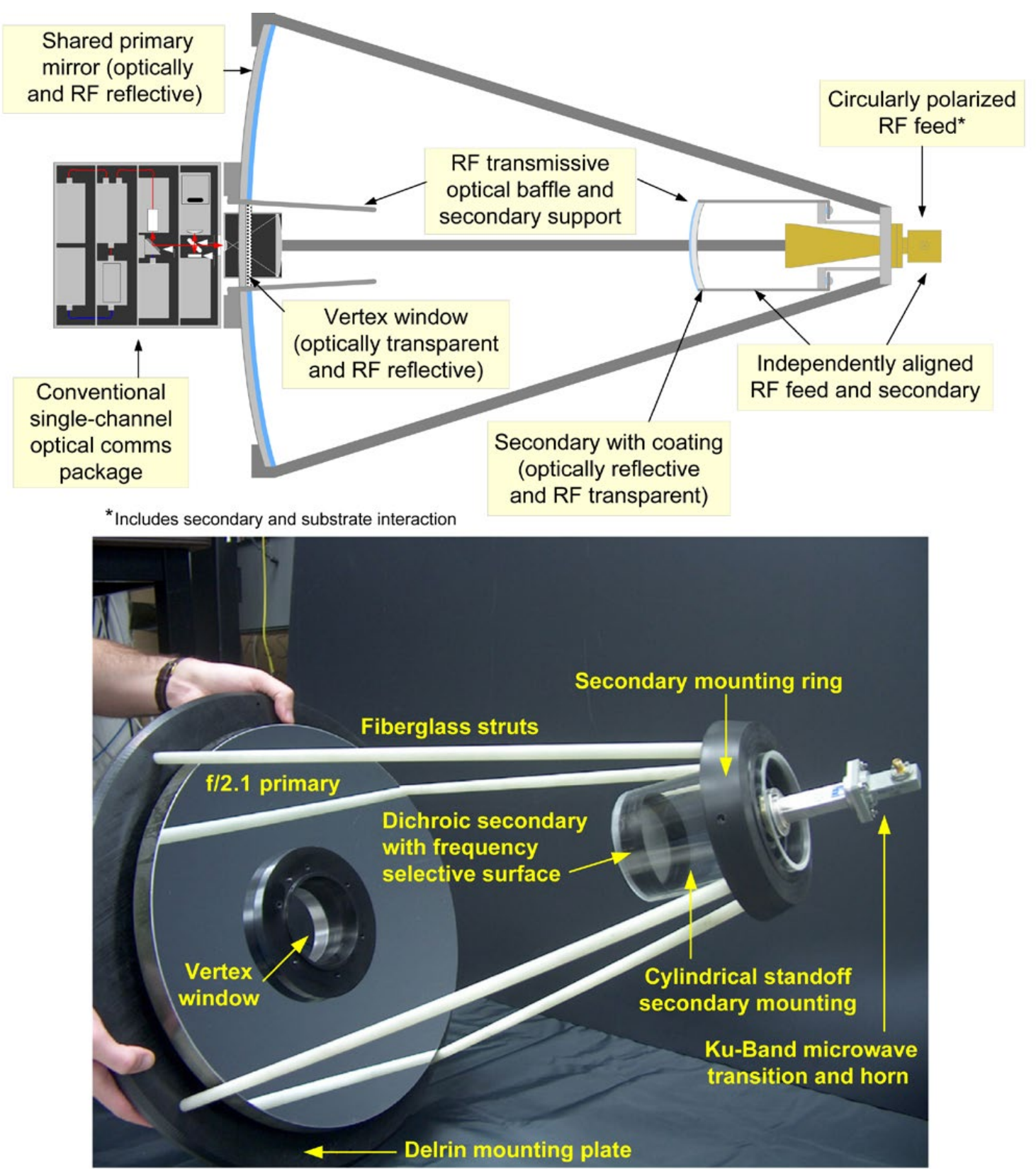

Figure 3.-Integrated RF and optical aperture. Schematic view is on the top and mock-up is on the bottom.

\subsection{Systems Engineering Trades Methodology}

The systems engineering trade methodology optimizes spacecraft aperture versus pointing error and space loss and minimizes SWaP for a given level of performance, by introducing dual-band materials innovation to reduce SWaP. Parametric analysis jointly employs mission and technologydriven parameters such as transmitter power, received power, antenna/telescope aperture, and pointing jitter, and a detailed phenomenology model for path loss, component noise, and receiver site availability statistics. Using the link equation for setting optical link requirements, the signal-to-noise ratio (SNR) varies with range differently within certain link regimes depending on the relative contributions of transmitter, receiver, and background noise. It also depends on a trade between pointing jitter and space loss that sets the antenna aperture optimally.

Once the required transmitter power is known, the required bus power can be derived, given the achievable laser wall-plug efficiency and optical terminal power supply mass. Optimization requires the sum of these to be minimized subject to a fixed transmitter power proportional to their product. From this antenna areal density can be determined 
and hence material selection minimizing the pointing jitter to be $\sim 1 / 3$ the Rayleigh limit ensures that it will not dominate implementation losses. This approach yields an RMS jitter requirement of $\sim 1.2 \mu \mathrm{rad}$ for a $0.53 \mathrm{~m}$ aperture, and $300 \mathrm{nrad}$ for a $1.32 \mathrm{~m}$ aperture at Mars. Previous developments have pushed more risk onto the ground segment while minimizing mass and aperture of the optical terminal separately from the $\mathrm{RF}$ channel. Our proposal is to make a larger dual-band aperture using lightweight materials to reduce mass by bringing the two bands to a common boresighted aperture.

The priority given to an optical or RF channel may be approximately determined a priori for an overall mission or it can be estimated more dynamically in real-time. It depends on a number of factors, including: ephemeris (range and angle); relative noise levels; atmospheric turbulence; cloud-free-lightof-sight availability; mission data-demand schedules; site diversity; diurnal stability; round trip delays; and other physical effects. If the optical band is given priority, the RF is used as a backup when availability is compromised. If RF is given priority, the optical augments for higher demand if the above parameter values allow. A path loss management scheme would jointly apply to the RF and optical bands. One of the principal reasons for dual-band is to compensate for the loss of optical ground receiver availability. Even with site diversity, availability asymptotically approaches only about 98 percent worldwide. Thus, RF provides a complementary highgain alternative to the optical channel for adverse or overcast weather.

The pointing, acquisition, tracking and stabilization (PATS) subsystem initiates and maintains the optical downlink. We have assumed that the spacecraft attitude control system (ACS) supports coarse pointing and tracking control in 1 to $10 \mathrm{mrad}$ range with a $1 \mathrm{~Hz}$ bandwidth, allowing body mounting of a dominant antenna with respect to the spacecraft bus. Fine steering mirrors (FSMs) must achieve $\leq 1 \mu \mathrm{rad}$, assuming reaction wheels are the primary source of platform vibration. The spacecraft needs to be optimally designed with these requirements in mind because they are demanding and costly. Thus, FSM requirements are approximately $\geq 33 \mathrm{~dB}$ from 0.5 to $\sim 200 \mathrm{~Hz}$ bandwidth, depending on the disturbance spectrum and optical bench transmissibility. Minimizing optical terminal mass using lightweight materials, however, has two challenges: 1) Achieving the desired passive transmissibility and thermal properties without raising resonant frequencies and possibly reducing thermal response times, which would make active compensation even more challenging; and 2) Selecting the lowest mass materials in thinner and more sparse designs with mature and repeatable fabrication processes.

Analysis of a large (1-m) aperture spacecraft mass allocation budget suggests that a mass reduction of over 75 percent can be achieved in the antenna and support structure over a silicon carbide design. The use of carbon fiber composites (CFCs) with nominal areal densities $<10 \mathrm{~kg} / \mathrm{m}^{2}$ can be achieved at low risk up to a $1.4 \mathrm{~m}$ aperture. Several options for the antenna/telescope design have been considered, including a longeron cruciform approach, a Meinel endostructure, and even a rigidized inflatable optical tube assembly. In all cases all-dielectric parts (except for the microwave feed-horn) would be used and require active selfmetering to correct and maintain coarse pointing. Some of these designs are also amenable to deployment from an EELV secondary payload adapter (ESPA ring) which has an inside diameter $>1.5 \mathrm{~m}$.

All three design concepts are based on an axially symmetric Cassegrain co-boresighted system with a direct-fed primefocus microwave horn that can operate down to Ku-band. The key dual-band features include a dichroic vertex plate (such as indium tin oxide (ITO)) to allow optical transmission and RF reflection and a FSS dichroic secondary to transmit RF and reflect optical wavelengths. Key challenges are implementing a dual-band antenna at RF frequencies less than Ku-band, and high precision optical surface quality $(<\lambda / 10 \mathrm{RMS})$. Other design methodologies have been considered, including an optical Cassegrain with an embedded RF patch array antenna and a dual-curvature primary for offset $\mathrm{RF}$ and optical antennas. To exploit these concepts, several thin-film and composite materials may be considered, including consideration of their skin depth and surface roughness.

\subsection{Critical Path to Implementation}

The desired dual-band antenna/telescope features are: a scalable fully-shared common aperture dual-band antenna/telescope with high mechanical rigidity, thermal stability, low vibration transmissibility, $<\lambda / 10$ RMS surface roughness, minimal scatter for near sun pointing, and an ultralightweight optical shroud.

Key questions to answer in order to achieve the best operational performance are:

1. What is the optimal aperture and SWaP given the downlink laser transmitter power?

2. What is the lowest risk, lowest areal density antenna material?

3. Can 300 nrad RMS jitter be achieved from Mars and what is its cost burden?

4. What is the link margin crossover point in range between Ka and optical bands?

5. What is the optimal channel utilization plan for $\mathrm{Ka}$ and optical bands, given site diversity, latency, fades, cloudfree line-of-sight (CFLOS), schedule, and data volume requirements?

6. What are the long term architecture and payload implications of combining the optical capability with the given X-band RF system for telemetry, tracking \& 
command (TT\&C), thus entirely offloading the Ka-band capability?

In addition to the above system engineering questions there are several risk reduction demonstration tasks that should be conducted in close coordination with the system engineering trades identified below.

1. Optimize downlink terminal performance with respect to aperture and pointing error using analytical and statistical method

2. Minimize SWaP, while maintaining downlink performance and aperture

3. Simulate long and short-term joint downlink-loss statistics for single and multiple ground receiver sites to optimize total data volume transferred using dual-band

4. Measure vertical or near-vertical path turbulence fades and CFLOS statistics for concurrent RF/ optical channel operations using extant spacecraft corner reflectors and validate simulations as required

5. Simulate and validate the minimal RMS jitter achievable with beacon track given expected time-of-flight latencies and point-ahead biases

6. Address technology risk reduction strategies for specific components and properties to support dual-band TRL mitigation, including:

a. Measuring the skin depth of dual-band primary materials (witness samples) for $\mathrm{Ka}$ and optical bands to minimize losses in both

b. Verify/validate $<\lambda / 10 \mathrm{RMS}$ surface roughness for a CFC primary and secondary in thinner lightweight configurations and assess any print-through, thermal, and vibrational effects

c. Measure and maximize optical and RF efficiencies of dichroic elements in dual-band design and the effects of thin-film properties and FSS patterning.

\subsection{The Plan Forward}

In FY12, NASA established an effort named the Integrated Radio and Optical Communications (iROC) payload to directly address this combined approach with a target towards deep space missions. In addition to aperture sharing, other component level integrations are being considered to minimize SWaP burden on the spacecraft such as with the digital core processor for encoding and modulation, sub-micron ASIC devices, PATS, avionics and thermal and structural element reuse. Each of the elements of the system need to be methodically traded through a systems engineering process in order to correctly identify the most substantial impacts on the overall SWaP savings and determine a set of optimal solutions. The realization of the iROC payload will enable a dual-band RF and optical trunk line link from a Mars orbiter back to Earth; high speed science data to support transmission from various deployed orbiting and roving assets.

The iROC evolutionary approach of enhancing the RF architecture with optical capability will offer a bridge to migrate towards optical communications, while continuing to serve the existing infrastructure. Each component within the payload will be examined to determine where reuse between the RF and optical systems may take place, and a metric assigned to evaluate the overall $\mathrm{SWaP}$ impact. As a whole this analytical model will be compared against flying fully separable payloads to establish the complete savings of the integrated approach. An overall system diagram is shown in Figure 4.

The iROC will address several key questions, including:

1. Which integration should take place between the optical and $\mathrm{S} / \mathrm{X} / \mathrm{Ka}$ band RF frequencies?

2. Separate or combined apertures for demonstration flight?

3. Body mounted versus gimbaled aperture, or a combination of both?

4. Potential software defined radio (SDR) growth to optical communications processing capability?

5. What synergies exist between iROC and other optical project accomplishments that may be leveraged to accelerate development?

6. In terms of disruption tolerant networking (DTN), what can be done to manage the RF and optical links to optimize service for the user?

7. What are the functional needs of the complex integrated system?

By accelerating the infusion of optical communications technology into the deep space architecture, Gbps services may be realized sooner, thus enabling capabilities such as multichannel or even 3-D high definition video feeds from the surface of Mars. Beyond those particular applications, the component level technology development accomplished through the iROC effort will benefit other future systems that demand lightweight low areal-density apertures, high speed RHBD processors, and nrad capable PATS systems. Such systems may include communications, or even scientific RADAR or LIDAR instrumentation payloads with potential commercial spinoff technologies. 


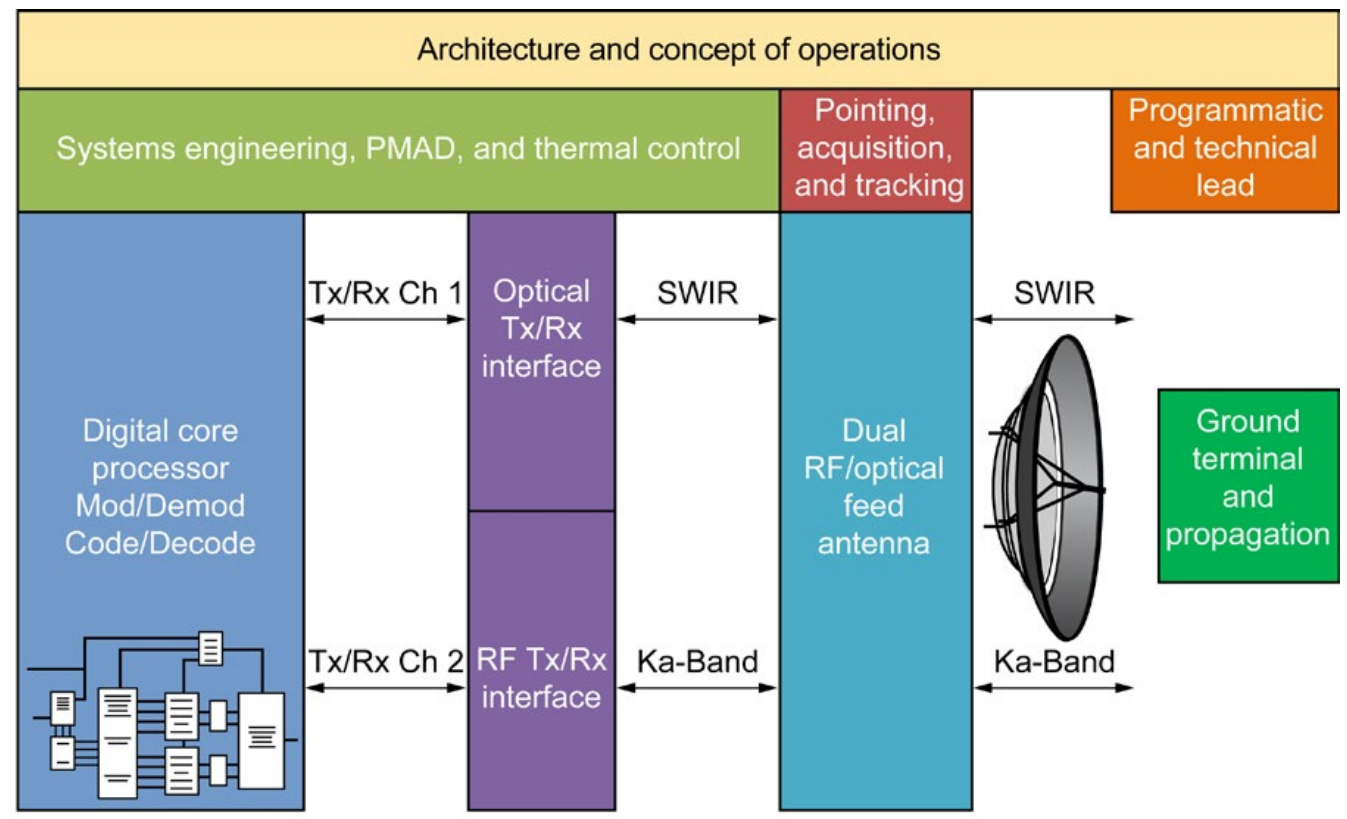

Figure 4.-iROC system diagram.

\subsection{Summary}

Current space based optical communications designs are built to minimize risk and not to maximize performance. A more rigorous system engineering approach is required to move optical communications more into the mainstream and justify the additional ground based infrastructure investment with scalable designs and FoMs in excess of $55 \mathrm{~dB}$ for Mars class missions. In the near term, integrated RF and optical designs with highly scalable architectures will allow optical communications systems to become more mainstream for U.S. spacecraft.

\section{References}

1. Hemmati, Hamid, ed., "Future Prospects and Applications," Chapter 7: Deep Space Optical Communications. Wiley-Interscience, Hoboken, 2006 pp. 643-644. Print. Deep-Space Communications and Navigation, Print

2. "Deep Space Optical Terminal Concept Review," DOT Concept Review, August 10-11 2010, Altadena, CA, Print

3. Hammiti, Hamid, Abhijit Biswas, and Don M. Boroson. "Prospects for Improvement for Interplanetary Laser Communication Data Rates by 30dB," Proceedings of the IEEE 95.10 (2007): 2082-091., Web

4. Lunar Laser Communications Demonstration CDR. Critical Design Review,12-16 July 2010, Burlington MA, Print
5. Mars Laser Communication Demonstration. Systems Requirement Review,12-13 October 2004, Columbia Hilton, Columbia MD, Print

6. Mars Laser Communications Demonstration Project. Concept Review, 16 January 2004, Goddard Space Flight Center, Greenbelt MD, Print

7. Noreen, Gary K., W. Dan Williams, O. Scott Sands, Michael Collins, Polly Estabrook, Himali Vyas, David D. Morabito, Robert J. Cesarone, Paul J. Timmerman, and Richard E. Hodges, "Mars Exploration Deep Space Return Link Scenario and Transmit System Optimization,” Proc. of 2005 International Astronautical Congress, Fukuoka, Japan, IAC-05-B3.6.04, Print

8. Taylor, Jim, Dennis K. Lee, and Shervin Shambayati, US. NASA. JPL. DESCANSO - Deep Space Communications and Navigation Systems/Mars Reconnaissance Orbiter Telecommunications. JPL/NASA, Sept. 2006, 20 Oct. 2010, Web $<$ http://descanso.jpl.nasa.gov/Publication/chapters_1 980.cfm? force external $=0>$.

9. Williams, W. Dan, Michael Collins, Don M. Boroson, James Lesh, Abihijit Biswas, Richard Orr, Leonard Schuchman, and O. Scott Sands. RF and Optical Communications: A Comparison of High Data Rate Returns From Deep Space in the 2020 Timeframe, Rep. no. NASA/ TM-2007-214459, March 2007, Print

10. Edwards, Clint L., Jonathan R. Bruzzi, and Bradley G. Boone. "Free-space high data rate communications technologies for near terrestrial space," Proc. SPIE Vol. 7091, Free-Space Laser Communications VIII, 10 - 14 August 2008, San Diego, California, Print 


\section{Biographies}

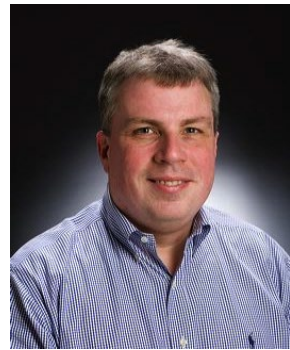

Karl B. Fielhauer is the former lead engineer of the MESSENGER RF communication system and flight operations that successfully achieved Mercury orbit insertion on March 18, 2011. He is also a Program Manager in the National Security Space Business Area at JHU/APL and is a member of the Principal Professional Staff. He received a B.S. in Electrical Engineering in 1985 from Lawrence Technological University in Southfield Michigan and an M.S. in Electrical and Computer Engineering in 2002 from The Johns Hopkins University Whiting School of Engineering in Baltimore Maryland. Before joining APL, Mr. Fielhauer worked for the National Security Agency and Litton Amecom Division in College Park, Maryland as the RF Lead for the EO-1 Mission. Since joining the JHU/APL Space Department in 1997, he has focused primarily on the design and development of RF telecommunications and navigation systems for civilian and national security spacecraft. Mr. Fielhauer was previously the NASA SCaN Deputy Technology Manager and is a member of IEEE.

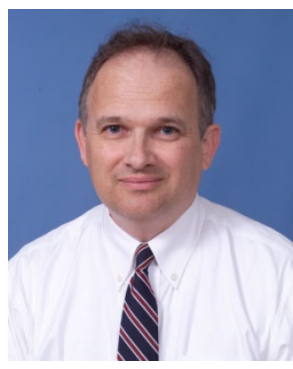

Bradley G. Boone is a Principal Professional Staff member of the Johns Hopkins University Applied Physics Laboratory, where he has been for the last 34 years. He received a B.S. degree in physics from Washington and Lee University in 1972, and a $\mathrm{PhD}$ in physics from the University of Virginia in 1977. He has broad technical expertise and has provided technical leadership in electrooptics with specialties in RF, IR and optical sensors for missile and spacecraft guidance, deep space optical communications, laser radar, optical signal processing, pattern recognition, superconducting electronics, and systems engineering. He has published over 70 papers and conference presentations, one textbook, and holds five U.S. patents. He has taught for the Johns Hopkins University Professional Graduate Programs in applied physics and electrical engineering for 29 years and was visiting professor in the Electrical and Computer Engineering Department in 1990-91.

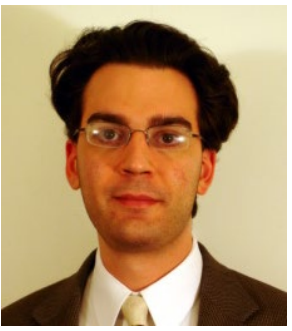

Daniel E. Raible is the principal investigator of the Integrated Radio and Optical Communications (iROC) payload effort at NASA Glenn Research Center where he is researching state of the art technologies that could be integrated together to realize a dual-band $\mathrm{RF}$ and optical terminal for deep space communications. He received a B.S. in Electrical Engineering in 2006 and an M.S. in Electrical Engineering in 2008 from the Fenn College of Engineering at Cleveland State University in Ohio, and recently defended his doctoral dissertation titled "Free Space Optical Communications with High Intensity Laser Power Beaming" in 2011 also at Fenn. Dr. Raible was hired by NASA in 2009, and works in the Antenna and Optical Systems Branch (RHA) within the Research and Technology Directorate at the center. 



\begin{tabular}{|c|c|c|}
\hline \multicolumn{2}{|c|}{ REPORT DOCUMENTATION PAGE } & $\begin{array}{l}\text { Form Approved } \\
\text { OMB No. 0704-0188 }\end{array}$ \\
\hline \multicolumn{3}{|c|}{$\begin{array}{l}\text { The public reporting burden for this collection of information is estimated to average } 1 \text { hour per response, including the time for reviewing instructions, searching existing data sources, gathering and maintaining the } \\
\text { data needed, and completing and reviewing the collection of information. Send comments regarding this burden estimate or any other aspect of this collection of information, including suggestions for reducing this } \\
\text { burden, to Department of Defense, Washington Headquarters Services, Directorate for Information Operations and Reports (0704-0188), } 1215 \text { Jefferson Davis Highway, suite } 1224 \text {, Anlington, VA } 222202-4302 \text {. } \\
\text { Respondents should be aware that notwithstanding any other provision of law, no person shall be subject to any penalty for failing to comply with a collection of information if it does not display a currently valid OMB } \\
\text { control number. } \\
\text { PLEASE DO NOT RETURN YOUR FORM TO THE ABOVE ADDRESS. }\end{array}$} \\
\hline $\begin{array}{l}\text { 1. REPORT DATE (DD-MM-YYYY) } \\
01-09-2012\end{array}$ & $\begin{array}{l}\text { 2. REPORT TYPE } \\
\text { Technical Memorandum }\end{array}$ & 3. DATES COVERED (From - To) \\
\hline \multirow{3}{*}{\multicolumn{2}{|c|}{$\begin{array}{l}\text { 4. TITLE AND SUBTITLE } \\
\text { Concurrent System Engineering and Risk Reduction for Dual-Band (RF/optical) Spacecraft } \\
\text { Communications }\end{array}$}} & 5a. CONTRACT NUMBER \\
\hline & & 5b. GRANT NUMBER \\
\hline & & 5c. PROGRAM ELEMENT NUMBER \\
\hline \multirow{3}{*}{\multicolumn{2}{|c|}{$\begin{array}{l}\text { 6. AUTHOR(S) } \\
\text { Fielhauer, Karl, B.; Boone, Bradley, G.; Raible, Daniel, E. }\end{array}$}} & 5d. PROJECT NUMBER \\
\hline & & 5e. TASK NUMBER \\
\hline & & $\begin{array}{l}\text { 5f. WORK UNIT NUMBER } \\
\text { WBS 439432.07.01.17.02 }\end{array}$ \\
\hline \multicolumn{2}{|c|}{$\begin{array}{l}\text { 7. PERFORMING ORGANIZATION NAME(S) AND ADDRESS(ES) } \\
\text { National Aeronautics and Space Administration } \\
\text { John H. Glenn Research Center at Lewis Field } \\
\text { Cleveland, Ohio 44135-3191 }\end{array}$} & $\begin{array}{l}\text { 8. PERFORMING ORGANIZATION } \\
\text { REPORT NUMBER } \\
\text { E-18339 }\end{array}$ \\
\hline \multirow{2}{*}{\multicolumn{2}{|c|}{$\begin{array}{l}\text { 9. SPONSORING/MONITORING AGENCY NAME(S) AND ADDRESS(ES) } \\
\text { National Aeronautics and Space Administration } \\
\text { Washington, DC 20546-0001 }\end{array}$}} & $\begin{array}{l}\text { 10. SPONSORING/MONITOR'S } \\
\text { ACRONYM(S) } \\
\text { NASA }\end{array}$ \\
\hline & & $\begin{array}{l}\text { 11. SPONSORING/MONITORING } \\
\text { REPORT NUMBER } \\
\text { NASA/TM-2012-217662 }\end{array}$ \\
\hline \multicolumn{3}{|c|}{$\begin{array}{l}\text { 12. DISTRIBUTION/AVAILABILITY STATEMENT } \\
\text { Unclassified-Unlimited } \\
\text { Subject Categories: } 33,36 \text {, and } 74 \\
\text { Available electronically at http://www.sti.nasa.gov } \\
\text { This publication is available from the NASA Center for AeroSpace Information, 443-757-5802 }\end{array}$} \\
\hline
\end{tabular}

\section{ABSTRACT}

This paper describes a system engineering approach to examining the potential for combining elements of a deep-space RF and optical communications payload, for the purpose of reducing the size, weight and power burden on the spacecraft and the mission. Figures of merit and analytical methodologies are discussed to conduct trade studies, and several potential technology integration strategies are presented. Finally, the NASA Integrated Radio and Optical Communications (iROC) project is described, which directly addresses the combined RF and optical approach.

\section{SUBJECT TERMS}

Optics; Photonics; Spacecraft communications

\begin{tabular}{|c|c|c|c|c|c|}
\hline \multicolumn{3}{|c|}{ 16. SECURITY CLASSIFICATION OF: } & \multirow{2}{*}{$\begin{array}{l}\text { 17. LIMITATION OF } \\
\text { ABSTRACT } \\
\text { UU }\end{array}$} & \multirow{2}{*}{$\begin{array}{l}\text { 18. NUMBER } \\
\text { OF } \\
\text { PAGES } \\
16\end{array}$} & \multirow{2}{*}{$\begin{array}{l}\text { 19a. NAME OF RESPONSIBLE PERSON } \\
\text { STI Help Desk (email:help@sti.nasa.gov) } \\
\text { 19b. TELEPHONE NUMBER (include area code) } \\
\text { 443-757-5802 }\end{array}$} \\
\hline $\begin{array}{l}\text { a. REPORT } \\
\text { U }\end{array}$ & $\begin{array}{l}\text { b. ABSTRACT } \\
\mathrm{U}\end{array}$ & $\begin{array}{l}\text { c. THIS } \\
\text { PAGE } \\
\text { U }\end{array}$ & & & \\
\hline
\end{tabular}



